\title{
Study on 3D Technology Application in Art Design
}

\author{
Yan Zhao ${ }^{1, \text { a }}$, Xuguang Yang ${ }^{1, b}$ \\ ${ }^{1}$ Environmental Management College of China, Qinhuangdao 066000, China \\ azhao1yan@163.com, ${ }^{\text {b } 883862 @ 163 . c o m ~}$
}

Keywords: 3D technology, Computer graphic, Modeling technology, Web 3D technology

\begin{abstract}
Computer 3D technology is the core content of interactive graphic, which is a grid science to calculate, process and display 3D graphic through algorithm. From the digital-processing 3D graphic establishes a set of systematic module database using computer graphic and coding, through which to realize the interactive design that using 3D to replace 2D and using virtual to replace reality. Meanwhile it also creates shot motion that cannot be obtained by traditional methods and dynamic integration of space 3D visualization. Therefore, computer 3D technology achieves wild and in-depth application in model construction, 3D website, and animation, etc.
\end{abstract}

\section{Introduction}

As a technology combine graphic production and graphic data, computer 3D technology gives people the ability to simulate, and to interactive 3D with real-time interaction. The visual reality technique, 3D simulation technology and visualization in scientific computing based on the 3D technology bring the technology to further development. With the rapid development of computer and information technology, 3D has become the hotspot on the combination of various disciplines such as computer science, engineering science and art design, which makes 3D technology greatly developed in digital art field.

\section{D module is the core of computer 3D technology}

In the real application of 3D model in the design, to turn the real object in daily life to 3D virtual model, 3D technology will using mathematics related to computer application to demonstrate a visual sense, which is the core work of computer graphic ---- 3D modeling. Currently, there are frequently-used 3D modeling software such as 3ds Max, Maya, WebGL, U3D, Image Modeler, etc. The data modeling and application from these software solve the data structure which displayed by computer on real objects including animation, craftwork design, spatial arrangement, that is, to reproduce the object in $3 \mathrm{D}$ world.

3D data collection is the acquisition of the surface data, which can obtain the coordinate of the object through 3D digitizer. Then it will connect the dot to grid and optimize them to get the final network model. Besides, it will also adopt direct numeric description and produce the model through parametric surface to get corresponding network model of the object. Moreover, it also can produce model of high-resolution through laser range finder, which involved in skinned-mesh algorithm. The models achieve through above methods is the surface model of the objects. But under some circumstances, we still need to use the internal information of the 3D model, through creating solid model technique combing with 3D modeling software to sketch out the 3D model in the computer. Here are some common ways listed as below（see Table 1)

Table 1 Methods categories and features of 3D modeling

\begin{tabular}{c|l}
\hline \multicolumn{1}{c|}{ Modeling Methods } & \multicolumn{1}{c}{ Model Attribute } \\
\hline polygon mesh modeling & $\begin{array}{l}\text { To put small triangle or quadrangle together for } \\
\text { complicated model }\end{array}$ \\
\hline
\end{tabular}




\begin{tabular}{l|l}
\hline Spline-based modeling & $\begin{array}{l}\text { Use spline to co-determine a smooth surface, which } \\
\text { feature is smooth without any steep or shrink. } \\
\text { Very-suitable for organic object modeling. }\end{array}$ \\
\hline Subdivision Modeling & $\begin{array}{l}\text { Combined the characteristics of the polygon modeling } \\
\text { with spline modeling, and smoothness of } \\
\text { easy-manipulate and smooth of spline into an organic } \\
\text { whole, which is a very efficient way of modeling. }\end{array}$ \\
\hline
\end{tabular}

The expressing effect of 3D modeling is more intuitive. Although there is a lot data structure of 3D modeling, targeted structure expression based on the collection, storage, management and analysis of 3D data and proper definition of data structure, embodies the inner connection of spatial and non-spatial relations of objects in 3D space, which plays an important role in the actual design application.

\section{The use of 3D technology in digital art}

Digital art refers to using digital technology and computer programs and so forth to analyze and edit pictures, videos and audios to finally get perfect updated-works. Digital art includes interactive media design, digital image art, virtual reality design, new media art and so forth. It is widely utilized in areas like graphic design, 3D animation, advertising, film and television design, and engineering visualization. With technology development, digital art is adopted and recognized by the public. Nowadays, Autodesk, world's leading design software company, has created many computer aided design software. Especially, 3D Max and Image Modeler has completely changed 3D design in computer graphic design, indoor and outdoor architectural drawings, and film and television animation.

Currently, 3D Max as the preferred software to make 3D model is still limited to computer games and architectural visual display in main application domains of 3D animation design. 3D Max provides very wide construction components as well as patch modeling tools components. When a complete object model is edited and transformed via various 3D Max tools, it can be put in a virtual 3D space. One advantage of 3D Max is the polygon tools components and the adjustment ability of UV coordinate mapping. It can locate and shape the object model according to the space coordinate axis and display the created model in the screen with grids. These grids are criss-cross on the object model surface, forming triangle patches. Numerous of triangle patches constitute object surface. The number of triangle patches decides the object's accuracy, smoothness and exquisite. Computer 3D technology can get color differences in different surface by calculating light on the object surface to make the object have a 3D display result. Due to this, 3D Max is widely used in products display, animation and other related fields. It is devoted to virtual reality animation, such as 3D virtual city plan, landscape display, 3D mechanical products design.

Image Modeler is specially designed modeling software for simplifying working process. It is an assisted modeling photo tool. By marking with points on the $2 \mathrm{D}$ object in the photo, the 3D modeling can be built up easily based on photo measurement. The established model can be imported into any main 3D software to design virtually. It can precisely record complicated geometry and material. Even very complicated model can be established efficiently by taking advantage of a small quantity of polygons. It can paste original object image on the model surface as materials. Therefore, the final model is very vivid. Figure 1 shows the process of establish 3D model with Image Modeler. 


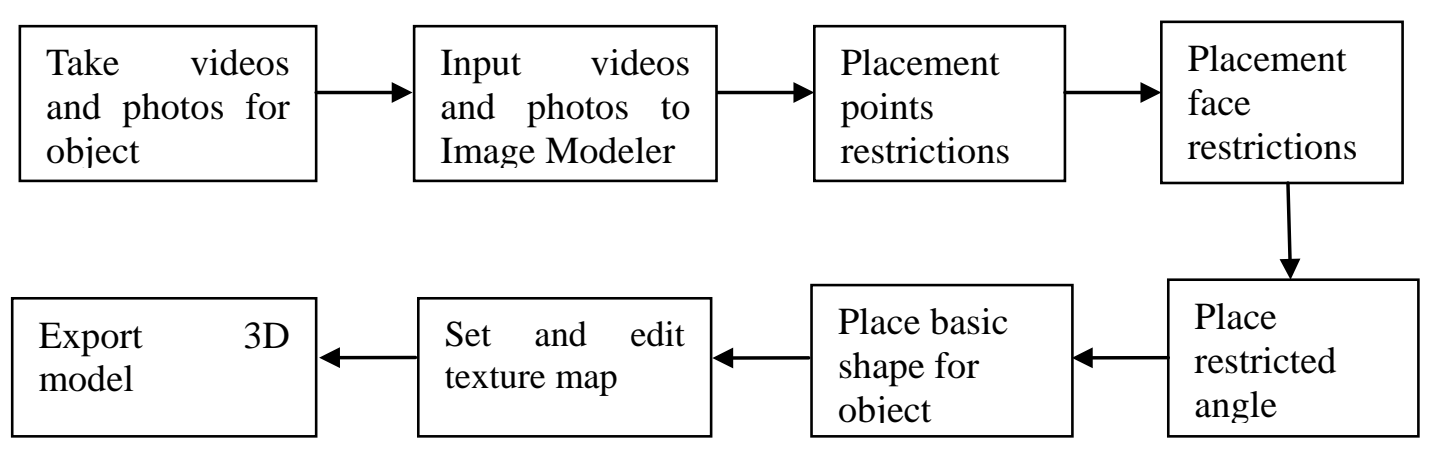

Fig.1 Modeling process with Image Modeler

\section{Analysis and application of Web3D technology}

Web3D is also named network 3D. It is a virtual reality technology to make tangible objects in reality displayed in virtual and 3D via Internet and interactively browsed. Recently, Web3D has become the standard of 3D files on Internet. The implementation technology and tools development based on Web3D has been valued among the industry. It can establish online 3D environment via various development tools and technologies, making users have autonomy when browsing and observe from their own perspectives. It also has many virtual special effects and interactive operation. All of these functions have attracted the attention from network application researchers.

Web3D can be simply regarded as the product of combining Web and 3D technology. It is the generic term of technology of realizing 3D image on Internet. In 2004, new international standard-X3D which was issued by Web3D association ad approved by ISO marked that Web3D has stepped into a new stage. X3D standard makes more Internet equipments have the functions of establishing, transferring and browsing 3D objects. No matter Web clients or broadcast station users with high performance can enjoy the technology advantages brought by X3D. In addition, under the basic frame of $\mathrm{X} 3 \mathrm{D}$, the interactive operation between different softwares is guaranteed, which finalize the mess of Internet 3D image standard. Now, Web3D has developed to a technology group and become an independent research area of Internet 3D application. Besides, it has become a visual management stage for developing and designing 3D webs and visualizing holographic image.

The core technology of Web3D which is stepping to practical stage is based on VRML, Java, XML, animation script, and stream transmission technology. It provides more flexible room for art design. Because different technology cores are adopted, different implementation technologies have different theories, features and application characters (Table 2).

Table 2 Comparison between core technique and features of Web3D

\begin{tabular}{l|l|l}
\hline $\begin{array}{l}\text { Core } \\
\text { technique } \\
\text { of Web3D }\end{array}$ & \multicolumn{1}{|c|}{ Technique features } & \multicolumn{2}{c}{ Application characteristics } \\
\hline & $\begin{array}{l}\text { To realize through coding, } \\
\text { 3D modeling, VRML } \\
\text { visual software. The } \\
\text { documents data maintain a }\end{array}$ & $\begin{array}{l}\text { High version browser require } \\
\text { pre-installed plug-in; Slow file transfer, } \\
\text { Long download time; low quality of } \\
\text { rendered image quality; weak in } \\
\text { integrated with other technology; }\end{array}$ \\
VRML & $\begin{array}{l}\text { large amount in simulating } \\
\text { 3D scenes. }\end{array}$ & $\begin{array}{l}\text { Suitable for 3D objects and scenes } \\
\text { display. }\end{array}$ \\
\hline Based on & $\begin{array}{l}\text { modeling and visual } \\
\text { software. The documents } \\
\text { data maintain small } \\
\text { amount in simulating 3D } \\
\text { Scenes. }\end{array}$ & $\begin{array}{l}\text { Require pre-installed plug-in; fast file } \\
\text { transfer, fast download time; good } \\
\text { quality of rendered image quality; } \\
\text { strong ability in integrated with other } \\
\text { technology; Suitable for 3D objects and } \\
\text { scenes display. }\end{array}$ \\
\hline
\end{tabular}




\begin{tabular}{l|l|l}
\hline & To realize through coding, & $\begin{array}{l}\text { No pre-installed plug-in; fast file } \\
\text { transfer, fast download time; premium }\end{array}$ \\
Based on & 3D modeling. The & $\begin{array}{l}\text { quality of rendered image quality; } \\
\text { documents data maintain } \\
\text { Java }\end{array}$ \\
small amount in simulating & 3D scenes. & $\begin{array}{l}\text { strong ability in integrated with other } \\
\text { technology; Suitable for 3D objects and } \\
\text { scenes display. }\end{array}$ \\
\hline
\end{tabular}

Three-dimensional modeling is the key to the Web3D graphics, the Web3D technology with its powerful interactivity and realistic as well as the characteristics of easy transmission in the network, demonstrating its unique advantages and potential in the network, with the rapid development of computer technology, the function of the Web3D technology will become more powerful and implemented technology will be more rich.

\section{Conclusion}

Science and technology are changing the way of art design and the development of information technology promoted the computer 3D interactive design technology and virtual reality technology. As a master of modern communications technology, 3D technique varies in the digital art information and design style, which act as a carrier realizing the real visual and virtual interaction. It also provides the technical support and implementation method toward a more proactive direction of diversification and integrated development and presents its new achievements in the field of art design.

\section{References}

[1] Y. F.Shen: Computer Graphics， (Tsinghua University Press， In Chinese 2011)

[2] Aotodesk Inc:3ds Max 8 Essentials: Aotodesk Media and Entertainment Courseware, (Focal Press, 2005)

[3] Y. J.Wang: Image processing and visualization of three, (Beijing University of Posts and Telecommunications Press, In Chinese 2011)

[4] C. P.Wang,Y.Gao: 3D computer graphics, (Mechanical Industry Press, 2010)

[5] Q.X.Zhang:Web3D technology and its application in product in simulation system, (Journal of Chongqing University, In Chinese 2002) 